\title{
Impact of Pentoxifylline and Vitamin E on Ribavirin-induced Hemolytic Anemia in Chronic Hepatitis C Patients: An Egyptian Survey
}

\author{
Mehdat Assem, M Yousri
}

\begin{abstract}
Background: The present study aimed to elucidate the impact of combined pentoxifylline and high-dose vitamin $E$ supplementation on Ribavirin (RBV)-induced hemolytic anemia in patients with chronic hepatitis $\mathrm{C}(\mathrm{CHC})$.
\end{abstract}

Patients and methods: A total of 200 treatment-naïve chronic $\mathrm{CHC}$ patients were randomized into two groups to receive either the standard antiviral therapy and pentoxifylline $(800 \mathrm{mg})$ and high-dose vitamin E (1000 IU) daily (combined group) or standard antiviral therapy and placebo (control group). They were followed-up to assess occurrence of anemia and virological responses respectively.

Results: Dose modification of RBV due to anemia was significantly lower in combined group (8.5\%) compared to control group $(21.5 \%)(p<0.05)$. Withdrawal from therapy due to severe anemia $(\mathrm{Hb}<8.5 \mathrm{gm} / \mathrm{dl})$ was recorded only in six $(28.6 \%)$ patients of the control group. Both end of treatment response (ETR) and sustained virological response (SVR) were significantly higher in combined group compared to control ( $p<0.05)$.

Conclusion: Pentoxifylline and vitamin E can ameliorate RBVassociated hemolysis; improve compliance and virologic clearance, when combined with the standard antiviral therapy in patients with $\mathrm{CHC}$.

Abbreviations: RBV: Ribavirin; ETR: End of treatment response; SVR: Sustained virological response.

Keywords: HCV, Ribavirin, Anemia, Pentoxifylline, Vitamin E.

How to cite this article: Assem M, Yousri M. Impact of Pentoxifylline and Vitamin E on Ribavirin-induced Hemolytic Anemia in Chronic Hepatitis C Patients: An Egyptian Survey. Euroasian J Hepato-Gastroenterol 2012;2(1):35-40.

Source of support: Nil

Conflict of interest: None declared

\section{INTRODUCTION}

The hepatitis $\mathrm{C}$ virus (HCV) is a major public health problem and a leading cause of chronic liver disease; with approximately $3 \%$ of the world's population affected. ${ }^{1,2}$ Hepatitis C-genotype-4 is the prevalent genotype in the Middle East. ${ }^{3}$ Its prevalence in Egypt is estimated to be more than $90 \%$ of chronic hepatitis C patients. ${ }^{4}$

Recently, Ribavirin (RBV) has been used in combination with pegylated interferon (IFN) as the most effective antiviral therapy against CHC. ${ }^{5}$ However, RBV-induced anemia represents a major limiting factor in the combined therapy of RBV and IFN. ${ }^{6}$
Anemia is likely to be related with extensive RBV accumulation in erythrocytes subsequent to possible active unidirectional transmembranous transport. RBV exerts its toxicity through an inhibition of intracellular energy metabolism and oxidative membrane damage, leading to an accelerated extravascular hemolysis by the reticuloendothelial system. ${ }^{7}$

Previous studies have shown that maintenance of highdose RBV by preventing hemolytic anemia using high supplementation doses of antioxidants like vitamin $\mathrm{E}$ and vitamin C, may lead to sustained virological response rate by pegylated IFN and RBV therapy, indicating that the dose of RBV is an important factor for effective combination therapy. ${ }^{8}$

Pentoxifylline which is a tri-substituted xanthine derivative has been used successfully in the treatment of peripheral arterial disease, ${ }^{9}$ diabetic nephropathy, ${ }^{10}$ diabetic retinopathy ${ }^{11}$ and coronary artery disease in diabetics, ${ }^{11}$ generally, in all conditions in which erythrocyte stiffness and increased blood viscosity are believed to play a role. ${ }^{11}$ Recently, its beneficial effects have been shown in different types of liver diseases. ${ }^{12}$ It has long been viewed as a potential antifibrotic agent, ${ }^{13}$ in addition to its modulating effect on insulin resistance through down regulation of tumor necrosis factor; it could be a potential mechanism for improvement in patients with nonalcoholic steatohepatitis (NASH). ${ }^{12,14,15}$ Our study aimed to evaluate the impact of combined pentoxifylline and high-dose vitamin $\mathrm{E}$ to the standard treatment of $\mathrm{HCV}$ to try ameliorating RBV-induced anemia, aiming to improve treatment adherence and virological response.

\section{PATIENTS AND METHODS}

\section{Patients' Selection}

This is a prospective, randomized, blind, controlled study, carried out in National Liver Institute Hospital, Menofyia University, Sheben AL koom, Egypt. The institute was established to provide specialized care for patients with liver diseases. The center receives patients from almost all regions of Egypt, besides patients from the neighboring Arab countries.

Between January and May 2008, 411 chronic hepatitis $\mathrm{C}(\mathrm{CHC})$ patients presented to the outpatient clinics. They 
were examined and screened for the eligibility of $\mathrm{HCV}$ treatment. The age of the patients ranged from 18 to 50 years and had detectable HCV RNA, with liver biopsy consistent with chronic hepatitis and significant fibrosis.

Patients were excluded if they had evidence for coexisting autoimmune liver disease, concurrent infection with hepatitis B virus or human immune-deficiency virus, presence of hepatocellular carcinoma, decompensated cirrhosis, patients on hemodialysis, significant systemic disorders, patients with hemoglobinopathies, uncontrolled diabetes mellitus, uncontrolled thyroid disease, a current or past history of alcohol abuse, major psychiatric conditions, hypersensitivity to interferon or Ribavirin, previous liver transplantation. Patients with baseline anemia $(\mathrm{Hb}<13 \mathrm{gm} / \mathrm{dl}$ for men and $<12 \mathrm{gm} / \mathrm{dl}$ for women), absolute neutrophil count (ANC) $<1500 / \mathrm{mm}^{3}$, platelet count $<75,000 / \mathrm{mm}^{3}$ or creatinine $>1.5 \mathrm{mg} / \mathrm{dl}$ were also excluded from the study.

This study complies with the standards of declaration of Helsinki and current ethical guidelines. After institutional review board approval and written informed consent were obtained, 200 subjects were recruited for the study. These were randomly assigned into two equal groups with the aid of a computer-generated table of random numbers.

\section{Treatment Regimens}

Each group received standard antiviral therapy; including peginterferon alfa- $2 \mathrm{~b}[(1.5 \mathrm{mcg} / \mathrm{kg} /$ week) (pegintron, Schering-Plough Co, Kenilworth, NJ, USA)] and ribavirin (Rebetol, Schering-Plough Co) in dose of 1000 or $1200 \mathrm{mg} /$ day depending on patient weight if less or more than $75 \mathrm{~kg}$ respectively. The duration of treatment was assigned for 48 weeks.

In the combined group, patients received highdose of vitamin E (vitamin E, Pharco Co, name of the city, Egypt) in dose of $1000 \mathrm{IU} /$ day and pentoxifylline $\left(\right.$ Trental ${ }^{\circledR} 400$
SR, product of Aventis pharma, Germany) in dose of 800 $\mathrm{mg}$ /day orally, in addition to standard anti-viral therapy. On the other hand, patients of the control group received starch tablets (placebo) and the standard antiviral therapy.

\section{Dose Modifications}

Medications doses were modified if hematological adverse events had occurred according to guidelines in Table $1 .{ }^{16}$ Growth factors such as erythropoietin and granulocyte colony-stimulating factor were not given in this study except when patients were beyond the dose modification criteria, and those were discarded from the study.

\section{Follow-up and End Points}

All subjects were monitored during peg-IFN and RBV treatment and for a further period of 24 weeks after the end of treatment. They had biweekly outpatient visits during the first month and monthly visits during the rest of the treatment period as well as during the 24-week follow-up period. At each visit, a physical examination was performed, the importance of treatment adherence was explained, adverse effects were recorded, and biochemical tests and blood counts were performed. The efficacy to standard antiviral therapy was defined as undetectable HCV RNA level by PCR at 12 weeks (early virological response, EVR), at the end of treatment (ETR) and after 24 weeks follow-up (sustained virological response, SVR).

The primary end point of our study was to complete the study protocol without major dose reduction due to anemia, while secondary end points were the occurrence of treatment complication necessitating withdrawal or antiviral treatment failure.

\section{STATISTICAL ANALYSIS}

Data was statistically analyzed using SPSS (statistical package for social science) program version 17 for windows.

\section{Table 1: Guidelines for dose modification and discontinuation of pegiinterferon or peginterferon and ribavirin}

\begin{tabular}{lll} 
Laboratory values Peg & Pegintron & Rebetol \\
\hline $\begin{array}{l}\text { Hemoglobin } \\
<10.0 \mathrm{gm} / \mathrm{dl}\end{array}$ & - & Decrease by $200 \mathrm{mg} / \mathrm{day}$ \\
$<8.5 \mathrm{gm} / \mathrm{dl}$ & Permanently discontinue & Permanently discontinue \\
\hline $\begin{array}{l}\text { White blood counts } \\
<1.5 \times 10^{9} / \mathrm{l}\end{array}$ & Reduce by $50 \%$ & - \\
$<1.0 \times 10^{9} / \mathrm{l}$ & Permanently discontinue & Permanently discontinue \\
\hline $\begin{array}{l}\text { Neutrophil } \\
<0.75 \times 10^{9} / \mathrm{l}\end{array}$ & Reduce by $50 \%$ & - \\
$<0.5 \times 10^{9} / \mathrm{l}$ & Permanently discontinue & Permanently discontinue \\
\hline $\begin{array}{l}\text { Platelets counts } \\
<80 \times 10^{9} / \mathrm{l}\end{array}$ & Reduce by $50 \%$ & - \\
$<50 \times 10^{9} / \mathrm{l}$ & Permanently discontinue & Permanently discontinue \\
\hline
\end{tabular}


Quantitative data were presented as mean \pm SD. Qualitative data were presented as relative proportions. Student t-test and Mann-Whitney test were used to compare means and medians for quantitative variables where appropriate. The association between the categorical variables was assessed by using the Chi-square test or Fisher exact test. $\mathrm{p}<0.05$ was considered as statistically significant.

\section{RESULTS}

\section{Basal Patients' Profile and Laboratory Data}

Demographic features, laboratory and histological staging in both studied groups were presented in Table 2. There were no statistical difference among both groups as regard mean age, sex ratio, mean body mass index, basal hematological features and blood chemistry.

Patients with fibrosis of F1/F2 and F3/F4 were distributed almost evenly between patients receiving combination therapy and control therapy (Table 2). Also there was no statistical difference regarding numbers of patients receiving initial Ribavirin dosage (either 1000 or $1200 \mathrm{mg} /$ day) between both groups ( $\mathrm{p}>0.05)$.

\section{Efficacy and Safety}

Number of patients who completed the study protocol (48 weeks) were comparable between both studied groups ( $83 \%$ in combined group $v s 79 \%$ in control group, $p>0.05$ ) (Table 3). In combined group, 66 patients completed the protocol without dose modification of either peginterferon or ribavirin, while seven patients needed ribavirin dose modification due to occurrence of mild anemia $(\mathrm{Hb}>8.5$ gm\%). In addition; both drugs were reduced in five patients due to combined anemia, neutropenia and thrombocytopenia of this group (Table 3). Seventeen patients in the combined group were dropped out of the study; none of them had hematological complications (Table 4). No complications related to either vitamin $\mathrm{E}$ (heart failure, coagulopathy and gastrointestinal effects) or pentoxifylline (cardiac arrhythmia, dizziness and gastrointestinal effects) were recorded during study protocol, except some cases with mild flushing and/or headache not necessitating dose modification or discontinuation.

In the control group, 54 patients completed study protocol without dose modification of both drugs, while 17 patients needed ribavirin dose modification due to occurrence of mild anemia, and another four patients needed reduction of both drugs due to combined blood cytopenias. Twenty-one patients $(21 \%)$ in the control group were dropped out of the study, with anemia as the cause of discontinuation in six patients (Table 4).

\begin{tabular}{|lcc}
\hline \multicolumn{2}{|c|}{ Table 3: Course of antiviral treatments } \\
$\begin{array}{c}\text { Combined } \\
\text { group }\end{array}$ & $\begin{array}{c}\text { Control } \\
\text { group }\end{array}$ \\
\hline Patients continuing study protocol & & \\
$\quad$ With full dose of both drugs & 66 & 54 \\
Ribavirin reduction & 7 & 17 \\
Interferon reduction & 5 & 4 \\
Reduction of both drugs & 5 & 4 \\
Patients discontinuing study protocol & 17 & 21 \\
$\quad$ With dose reduction & 17 & \\
\hline
\end{tabular}

Table 2: Comparison of patient profiles and laboratory data

\begin{tabular}{|c|c|c|c|}
\hline Variables & Combination group number: 100 & Control group number: 100 & $p$-value \\
\hline Age (years) & $44.3 \pm 12.3$ & $45.9 \pm 10.3$ & NS \\
\hline Sex: Male, female & 69:31 & $58: 42$ & NS \\
\hline Body mass index $\left(\mathrm{kg} / \mathrm{m}^{2}\right)$ & $28.6 \pm 5.7$ & $27.9 \pm 6.1$ & NS \\
\hline \multicolumn{4}{|l|}{ Peripheral blood cell count } \\
\hline Hemoglobin (gm/dl) & $14.48 \pm 1.64$ & $14.79 \pm 1.38$ & NS \\
\hline Leukocyte $\left(\times 10^{3} / \mathrm{ml}\right)$ & $6.64 \pm 1.85$ & $6.67 \pm 1.9$ & NS \\
\hline Platelet $\left(\times 10^{3} / \mathrm{ml}\right)$ & $198.73 \pm 62.4$ & $192.21 \pm 76.32$ & NS \\
\hline \multicolumn{4}{|l|}{ Blood biochemistry } \\
\hline AST (IU/I) & $72.55 \pm 46.82$ & $73.19 \pm 39.47$ & NS \\
\hline ALT (IU/I) & $86.71 \pm 67.92$ & $79.66 \pm 70.13$ & NS \\
\hline Bilirubin (mg/dl) & $0.91 \pm 0.62$ & $1.02 \pm 0,66$ & NS \\
\hline Creatinine (mg/dl) & $1.13 \pm 0.42$ & $0.99 \pm 0.38$ & NS \\
\hline Iron (mcg/dl) & $82.7 \pm 60.7$ & $85.6 \pm 58.8$ & NS \\
\hline Ferritin $\mathrm{ng} / \mathrm{ml}$ & $132.7 \pm 42.8$ & $129.64 \pm 39.24$ & NS \\
\hline \multicolumn{4}{|l|}{ Liver histology } \\
\hline F1-F2 & 68 & 62 & \\
\hline F3- F4 & 32 & 38 & NS \\
\hline \multicolumn{4}{|c|}{ HCV-RNA PCR viral load IU/ml } \\
\hline$<400,000 \mathrm{IU} / \mathrm{ml}$ & 66 & 58 & \\
\hline$>400,000 \mathrm{IU} / \mathrm{ml}$ & 34 & 42 & NS \\
\hline \multicolumn{4}{|l|}{ Ribavirin dosage } \\
\hline 1000 mg/day & 38 & 29 & \\
\hline 1200 mg/day & 62 & 71 & NS \\
\hline
\end{tabular}

NS: Not significant 


\begin{tabular}{|c|c|c|c|}
\hline Variables & Combined group number: 17 & Control group number: 21 & Significance \\
\hline Thyroiditis & 2 & 2 & NS \\
\hline Autoimmune disease aggravation & 2 & 1 & NS \\
\hline Skin eruption & 3 & 1 & NS \\
\hline Depression or anxiety & 3 & 2 & NS \\
\hline Fatigue & 2 & 1 & NS \\
\hline Anemia $\mathrm{Hb}<8.5 \mathrm{gm} \%$ & - & 6 & $p<0.05$ \\
\hline Neutropenia ANC $<500 / \mathrm{mm}^{3}$ & - & 3 & $p<0.05$ \\
\hline Thrombocytopenia platelet $<25 \times{ }^{10} / \mathrm{mm}^{3}$ & - & 2 & NS \\
\hline Retinal hemorrhage & 1 & - & NS \\
\hline Nephritic syndrome & - & 1 & NS \\
\hline Hearing disturbance & 1 & 1 & NS \\
\hline Economical problems & 3 & 1 & NS \\
\hline
\end{tabular}

NS: Not significant

\section{Hematological Changes}

As regard the changes in hematological profile during treatment protocols, combined group showed significantly less reduction of hemoglobin levels, leukocytes and platelets counts compared to control group $(\mathrm{p}=0.01, \mathrm{p}=0.009$ and $\mathrm{p}=0.01$ respectively) (Figs 1 to 3 ).

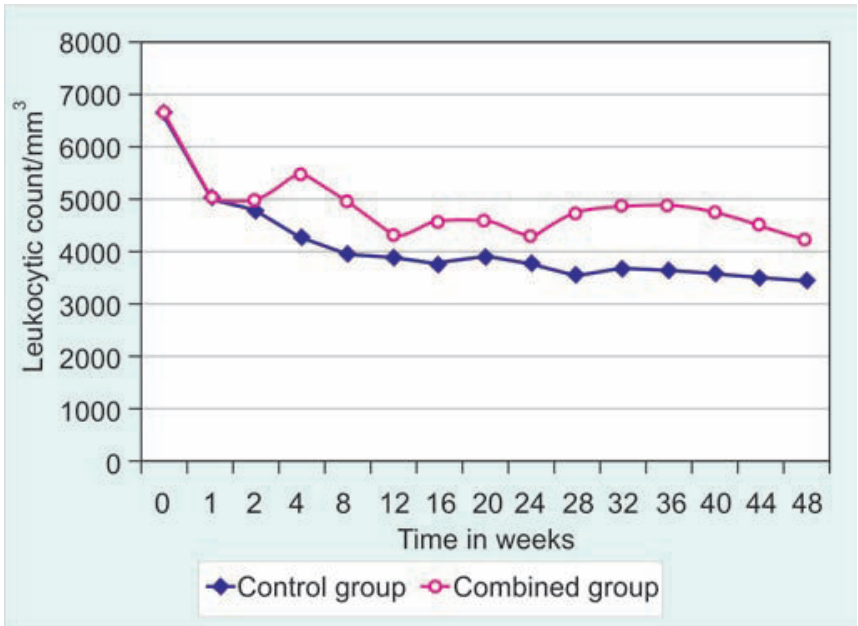

Fig. 1: Kinetics of mean leukocytic counts among the studied groups

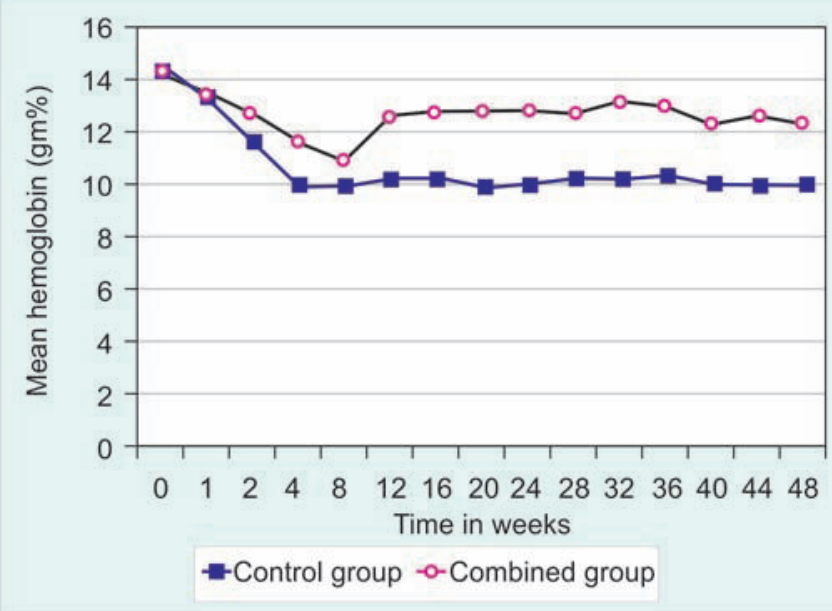

Fig. 2: Kinetics of mean hemoglobin percentage among the studied groups

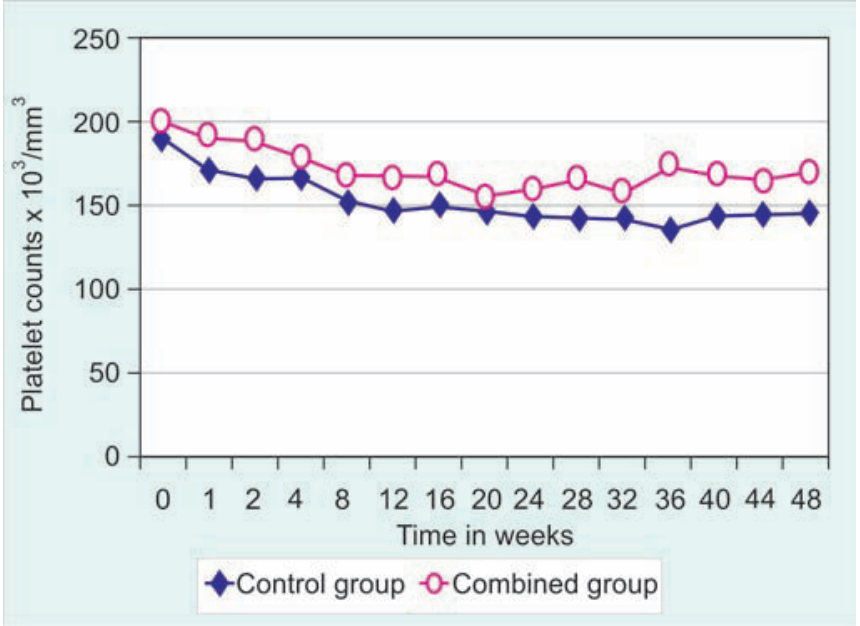

Fig. 3: Kinetics of mean platelet counts among the studied groups

\section{Virological Response}

No significant difference was found as regard EVR while, both ETR and SVR were significantly higher in the combined group than those of the control group (71 vs $56 \%, \mathrm{p}<0.05$ and $66 v s 49 \%, \mathrm{p}<0.05)$ and per protocol analysis $(85.5 v s$ $70.9 \%, \mathrm{p}<0.05$ and 79.5 vs 62\%, $<<0.05$ ) (Table 5).

\begin{tabular}{|c|c|c|}
\hline Response & $\begin{array}{c}\text { Combined } \\
\text { group }\end{array}$ & $\begin{array}{l}\text { Control } \\
\text { group }\end{array}$ \\
\hline End of treatment & 71 & 56 \\
\hline Sustained virological response & 66 & 49 \\
\hline
\end{tabular}

\section{DISCUSSION}

In this study, we elucidated for the first time that combined pentoxifylline and vitamin E significantly ameliorate the reduction of hemoglobin level during treatment with peginterferon and ribavirin in CHC Egyptian patients with significant improvement in both ETR and SVR rates in a randomized controlled trial. 
Clinical evidence has shown the importance of ribavirin in the treatment of CHC patients, but this agent is associated with frequent adverse events, necessitating dose reductions and/or discontinuations. ${ }^{17}$ Ribavirin reductions, however, can have a negative impact on SVR. Thus, management of ribavirin toxicity, especially anemia, can allow patients to continue full-dose combination therapy with peginterferon and ribavirin, aiming for enhancing their probability of attaining SVR. ${ }^{18}$

Previous studies showed that vitamin E might protect red blood cell membranes from oxidative damage due to ribavirin. ${ }^{19}$ However, while many advocate the potential benefits of antioxidants, including vitamin $\mathrm{E}$, on Ribavirininduced hemolysis, no systematic studies have been reported. $^{20}$

Based on previous reports of pentoxifylline in increasing erythrocyte adenosine triphosphate levels, erythrocyte deformability, ${ }^{21}$ decreasing plasma fibrinogen and blood viscosity ${ }^{21}$ which lead to reduction of both hemolysis and pain crises in of sickle cell disease, ${ }^{22}$ we assumed that combination of pentoxifylline and vitamin E may be more effective in Ribavirin-induced hemolytic anemia.

In our study, the addition of pentoxifylline and vitamin $\mathrm{E}$ to peginterferon and ribavirin improved reduction in hemoglobin compared to patients taking only antiviral drugs (control group). This was similar to the results of a previous work done by Yasunori et al who showed addition of high doses of vitamin $\mathrm{E}$ and vitamin $\mathrm{C}$ could prevent hemolytic anemia during combination therapy with Ribavirin and IFNalfa-2b in patients with $\mathrm{CHC},{ }^{19}$ while Saeian et al recommended the addition of another water soluble antioxidant like $\mathrm{N}$-acetyl cysteine to vitamin $\mathrm{E}$, aiming to enhance its antioxidant protective effect on erythrocyte membrane. ${ }^{20}$

In our study, the protective impact of the combined therapy was seen through reduction of both neutrophils and platelet counts during treatment period which may point to the extended protective effect of this combination to prevent reticuloendothelial system (RES) destruction for different blood cells. It is suggested that pentoxifylline may increase filterability of different blood cells while passing through RES based on its proven role to increase filterability of red blood cells and decreased adherence to endothelial cells. ${ }^{21}$ Similar finding was reported by other group ${ }^{19}$ concerning the protective effect of antioxidants like vitamin $\mathrm{E}$ and vitamin $\mathrm{C}$ on platelet counts. They just attribute their results to antioxidant proprieties of the used vitamins.

Number of patients needed Ribavirin dose reduction was significantly less in combined group which reflect the protective role of adding pentoxifylline and vitamin $\mathrm{E}$ to standard treatment of HCV. This improved patient compliance and adherence to treatment was associated with significant improvement of both ETR and SVR rates in combined group, which highlighted the beneficial effect of this combination in increased compliance, maintained highdose of Ribavirin and may be the inhibitory effect of pentoxifylline on several proinflammatory cytokines in the liver like TNF-alpha, ${ }^{23}$ which might augment the antiviral role of peginterferon and Ribavirin.

Withdrawal from the study was comparable between studied groups. Anemia was the most significant cause of withdrawal in control group, while no specific complications related to either pentoxifylline or vitamin $\mathrm{E}$ were recorded. This reflects the safety of this combination when added in the used conditions to the standard treatment of $\mathrm{HCV}$ during the treatment protocol.

Previous reports denoted that administering erythropoietin can improve anemia caused by peginterferon and ribavirin therapy and is more effective than dose reduction at improving quality of life during treatment. ${ }^{24}$ However, erythropoietin, which is not approved by the US Food and Drug Administration (FDA) for use in patients with $\mathrm{HCV}$ infection, adds another parenteral drug to the patient's treatment regimen, and is associated with additional costs, inconvenience and potential side effects. ${ }^{24}$

We concluded that adding both pentoxifylline and vitamin E could ameliorate Ribavirin associated hemolysis; improving compliance and virologic clearance with combination therapy with pegylated interferon and Ribavirin in patients with chronic hepatitis C. The suggested combination was cheap, safe and effective and could replace the use of more hazards and expensive erythropoietin in our studied population, so worldwide use of this combination is recommended to verify their efficacy and safety in other genotypes of HCV patients.

\section{ACKNOWLEDGMENT}

The study was done in part by the financial support from National Liver Institute, Egypt. The authors would like to thank all staff members of Hepatology clinic-National Liver Institute for their cooperation in fulfilling this study.

\section{REFERENCES}

1. Williams R. Global challenges in liver disease. Hepatology 2006;44:521-26.

2. Shepard CW, Finelli L, Alter MJ, et al. Global epidemiology of hepatitis C virus infection. Lancet Infect Dis 2005;5:558-67.

3. Kamal SM, Nasser IA. Hepatitis C genotype 4: What we know and what we do not yet know? Hepatology 2008;47:1371-83. 
4. Ray SC, Arthur RR, Carella A, et al. Genetic epidemiology of hepatitis C virus throughout Egypt. J Infect Dis 2000;182: 698-707.

5. Hadziyannis SJ, Sette H Jr, Morgan TR, et al. PEGASYS International Study Group. Peginterferon-alpha 2a and ribavirin combination therapy in chronic hepatitis $\mathrm{C}$ : A randomized study of treatment duration and ribavirin dose. Ann Intern Med 2004;140:346-55.

6. D Franceschi L, Fattovich G, Turrini F, et al. Haemolytic anaemia induced by ribavirin therapy in patients with chronic hepatitis $\mathrm{C}$ virus infection: Role of membrane oxidative damage. Hepatology 2000;31:997-1010.

7. Russmann S, Grattagliano I, Portincasa P, et al. Ribavirininduced anaemia: Mechanisms, risk factors and related targets for future research. Curr Med Chem 2006;13:3351-57.

8. Adziyannis SJ, Sette H Jr, Morgan TR, et al. Peginterferon alpha $2 \mathrm{a}$ and ribavirin combination therapy in chronic hepatitis C: A randomized study of treatment duration and ribavirin dose. Ann Intern Med 2004;140:346-55.

9. Muir RL. Peripheral arterial disease: Pathophysiology, risk factors, diagnosis, treatment and prevention. J Vasc Nurs 2009;27:26-30

10. Leyva-Jiménez R, Rodríguez-Orozco AR, Ortega-Pierres LE, et al. Effect of pentoxifylline on the evolution of diabetic nephropathy. Med Clin (Barc) 2009;132:772-78.

11. Maiti R, Agrawal NK, Dash D, et al. Effect of pentoxifylline on inflammatory burden, oxidative stress and platelet aggregability in hypertensive type 2 diabetes mellitus patients. Vascul Pharmacol 2007;47:118-24.

12. Satapathy SK, Garg S, Chauhan R, et al. Beneficial effects of tumour necrosis factor-alpha inhibition by pentoxifylline on clinical, biochemical, and metabolic parameters of patients with non-alcoholic steatohepatitis. Am J Gastroenterol 2004; 99: 1946-52.

13. Raetsch C, Jia JD, Boigk G, et al. Pentoxifylline down regulates profibrogenic cytokines and procollagen I expression in rat secondary biliary fibrosis. Gut 2002;50:241-47.

14. Scheen AJ, Luyckx FH. Non-alcoholic steatohepatitis and insulin resistance: Interface between gastroenterologists and endocrinologists. Acta Clin Belg 2003;58:81-91.

15. Saglam K, Kilic R, Yilmaz MI, et al. Insulin resistance in patients with steatohepatitis. Hepatogastroenterology 2003;50:456-59.
16. Peg-intron (peginterferon alfa-2b) Prescribing Information and Medication Guide. (Accesse june 14, 2010, at: www. hcvadvocate.org/hepatitis/factsheets_pdf

17. Luca C, Grigore L, Vâpã A, et al. Adverse reactions of different treatments in chronic hepatitis C. Rev Med Chir Soc Med Nat Iasi 2009; 113:991-95.

18. Moraes Coelho HS, Villela-Nogueira CA. Predictors of response to chronic hepatitis C treatment. Ann Hepatol 2010;9 Suppl:54-60.

19. Kawaguchi Y, Mizuta T, Takahashi K, et al. High-dose vitamins $\mathrm{E}$ and $\mathrm{C}$ supplementation prevents ribavirin-induced haemolytic anaemia in patients with chronic hepatitis C. Hepatol Res 2007;37:317-24.

20. Saeian K, Bajaj JS, Franco J, et al. High-dose vitamin E supplementation does not diminish ribavirin-associated haemolysis in hepatitis $\mathrm{C}$ treatment with combination standard alpha-interferon and ribavirin. Aliment Pharmacol Ther. 2004;20:1189-93.

21. Sowemimo-Coker SO, Turner P. The effect of pentoxifylline on filterability of normal red blood cells and their adhesiveness to cultured endothelial cells. Eur J Clin Pharmacol 1985;29:55-59.

22. Sacerdote A. Treatment of homozygous sickle cell disease with pentoxifylline. J Natl Med Assoc 1999;91:466-70.

23. Gutierrez-Reyes G, Lopez-Ortal P, Sixtos S, et al. Effect of pentoxifylline on levels of pro-inflammatory cytokines during chronic hepatitis C. Scand J Immunol 2006;63:461-67.

24. McHutchison JG, Manns MP, Brown RS Jr, et al. Strategies for managing anaemia in hepatitis $\mathrm{C}$ patients undergoing antiviral therapy. Am J Gastroenterol 2007;102:880-89.

\section{ABOUT THE AUTHORS}

\section{Mehdat Assem (Corresponding Author)}

Associate Professor, Department of Hepatology and Gastroenterology National Liver Institute, Menofyia University, Sheben Al koom National Liver Institute: 32111, Egypt, Phone: 20105109581, Fax: 20482222743/2224586,e-mail: medassem68@yahoo.com

\section{Yousri}

Department of Hepatology, National Liver Institute, Menofyia University, Egypt 